\title{
A Novel Idea for Coil Collar Structures in Accelerator Superconducting Magnets
}

\author{
P. Fessia and D. Perini
}

\begin{abstract}
The dipoles for several different machines (LHC, SSC, HERA) were designed using nonmagnetic metallic collars to contain the superconducting coils. The coils are of two types, main and floating. This paper describes a structure with combined steel and plastic collars. Since the floating collars do not give an important contribution to the global rigidity of the dipole we propose to suppress them. The plastic collars are just fillers to limit the helium contained in the cold mass. Some data about thermoplastic materials to be possibly used for the collars are given and some estimations of mass and cost of this configuration are made. Finally the results of the tests of a 1-m-long twin aperture dipole with mixed steel-plastic collars are shortly described. The replacement of expensive alloys by high performance plastic in nonstructural components can be a cost-effective solution in view of future projects where superconducting magnets are involved and contained costs are a key issue.
\end{abstract}

Index Terms-Collar structure, polymers.

\section{INTRODUCTION}

$\mathbf{T}$ HE NON-MAGNETIC collars of an accelerator magnet are clamped around the coils during the collaring operation. Two different types of collars interlock around the coils to form the collared coils structure: the fixed collars and the floating collars (Fig. 1). The force transmitted to the floating collars by the compressed coils is transferred to the fixed collars via the packing rods. Finally all the reaction to the coil compression passes through the fixed collars and is taken by the collaring rods. The local deformation of the packing rod holes and the design clearance $(0-0.03 \mathrm{~mm})$ necessary to insert the packing rods decrease the contribution of the floating collars to the global stiffness of the collared coil structure. This paper assesses the possibility of reducing to zero the above mentioned contribution, taking the LHC dipole as a reference design. This is realized making the floating collars out of plastic instead of austenitic steel.

\section{The LHC DiPOLE STRUCTURE}

The LHC dipole cross section is shown in Fig. 1 and is defined by four main components:

- the coils, assembled with prestress inside the cavity defined by the collars

- the collars, clamped around the coils to maintain the coil prestress

Manuscript received September 24, 2001.

The authors are with CERN, Geneva CH (e-mail: \{Paolo.Fessia; Diego.Perini\}@cern.ch).

Publisher Item Identifier S 1051-8223(02)03459-0.

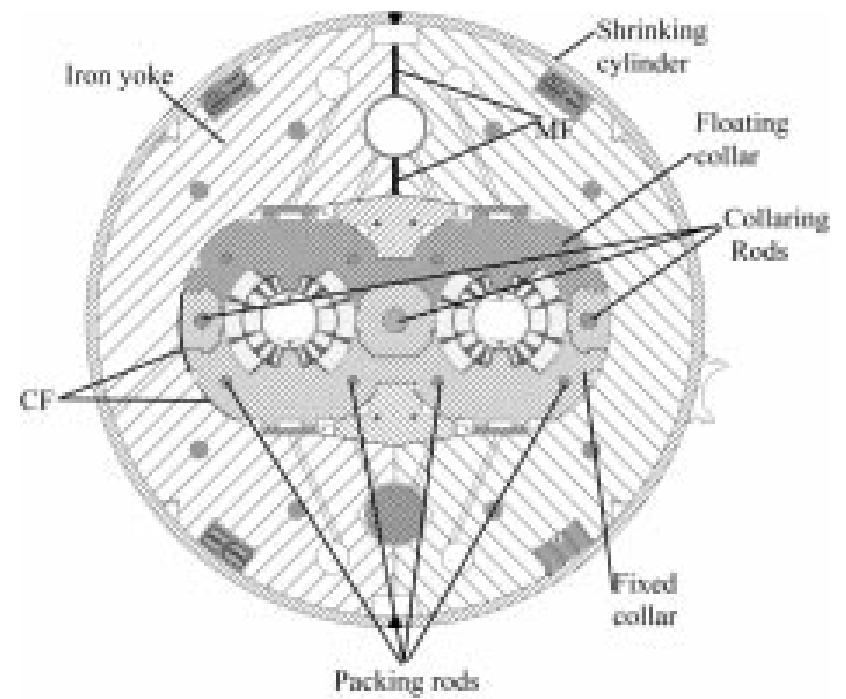

Fig. 1. The LHC main dipole cross section. MF is the mating force, CF is the contact force. They are the resultants of the forces exchanged along the highlighted surfaces.

- $\quad$ the iron yoke, split in two parts by the vertical gap

- the shrinking cylinder, that assures the driving force to keep the two iron yoke halves in contact.

The plastic collars will be smaller, having a profile in the shadow of the steel ones. In such a way no force will be carried and the different thermal contraction will have no influence. The plastic collars are stress free.

The behavior of the structure during its assembly and operation and the characteristics of the main components are discussed in detail in [1].

\section{THE FEA COMPARISON}

Finite element computations are carried out to compare the following structures:

MBP1T_I: fixed and floating collars in austenitic steel

MBP1T_MSP: fixed collars in austenitic steel, floating collars in plastic.

The analysis focuses on the assembled dipole at room temperature, the dipole at $1.9 \mathrm{~K}$ and zero field and the dipole at $1.9 \mathrm{~K}$ and field slightly above the nominal: $8.5 \mathrm{~T}$.

We started from the mesh and the optimized parameters of the MBP1T_I. A complete description of MBP1T_I can be found in [1]. Then the computations are carried out changing the floating collar material properties but leaving unchanged all the other parameters (i.e., iron yoke gap size, coil shims, etc.). 
TABLE I

Summary of the Results and Percentage DifFerence BetweEn the Austenitic Steel/Plastic (7-8 GPa) AND the Austenitic Steel Structure at 293 K. THE Forces ARE Given IN NEWTON PER QUAdRANT AND PER MILLIMETER OF THICKNESS

\begin{tabular}{lccc}
\hline & $\begin{array}{c}\text { Full steel } \\
\text { structure }\end{array}$ & $\begin{array}{c}\text { Mixed } \\
\text { structure }\end{array}$ & $\begin{array}{c}\text { Difference } \\
(\%)\end{array}$ \\
\hline $\begin{array}{l}\text { Compressive stress } \\
\text { Outer layer [MPa] }\end{array}$ & 67 & 62 & -7 \\
\hline $\begin{array}{l}\text { Compressive stress } \\
\text { Inner layer [MPa] }\end{array}$ & 65 & 60 & -7 \\
\hline Mating force [N/mm] & 1126 & 1219 & 8 \\
\hline Contact force [N/mm] & 1415 & 1059 & -25 \\
\hline Cylinder stress [MPa] & 154 & 152 & -1 \\
\hline
\end{tabular}

TABLE II

Summary of the Results AND PERCENTAGe DifFerence BetweEn the Austenitic Steel/Plastic (7-8 GPa) and the Austenitic STEEL Structure AT $1.8 \mathrm{~K}$. The Forces ARE GIVEN IN NEWTON PER QUADRANT AND PER MILLIMETER OF THICKNESS

\begin{tabular}{lccc}
\hline & $\begin{array}{c}\text { Full steel } \\
\text { structure }\end{array}$ & $\begin{array}{c}\text { Mixed } \\
\text { structure }\end{array}$ & $\begin{array}{c}\text { Difference } \\
(\%)\end{array}$ \\
\hline $\begin{array}{l}\text { Compressive stress } \\
\text { Outer layer [MPa] }\end{array}$ & 46 & 43 & -6 \\
\hline $\begin{array}{l}\text { Compressive stress } \\
\text { Inner layer [MPa] }\end{array}$ & 46 & 42 & -9 \\
\hline Mating foree [N/mm] & 3385 & 3360 & -1 \\
\hline Contact force [N/mm] & 140 & 59 & -58 \\
\hline Cylinder stress [MPa] & 326 & 325 & -0.4 \\
\hline
\end{tabular}

TABLE III

Summary of the Results and PERCENTAGe DifFerence BetweEn the Austenitic SteEl/Plastic (7-8 GPa) and the Austenitic Steel Structure AT $1.8 \mathrm{~K} 8.5 \mathrm{~T}$. THE Forces ARE Given IN NEWTON PER QUADRANT AND PER MILLIMETER OF THICKNESS

\begin{tabular}{lccc}
\hline & $\begin{array}{c}\text { Full steel } \\
\text { structure }\end{array}$ & $\begin{array}{c}\text { Mixed } \\
\text { structure }\end{array}$ & $\begin{array}{c}\text { Difference } \\
(\%)\end{array}$ \\
\hline $\begin{array}{l}\text { Compressive stress } \\
\text { Outer layer [MPa] }\end{array}$ & 77 & 75 & -3 \\
\hline $\begin{array}{l}\text { Compressive stress } \\
\text { Inner layer [MPa] }\end{array}$ & 66 & 62 & -6 \\
\hline Mating force [N/mm] & 2998 & 2883 & -4 \\
\hline Contact force [N/mm] & 697 & 688 & -1 \\
\hline Cylinder stress [MPa] & 327 & 327 & 0 \\
\hline
\end{tabular}

\section{A. Finite Element Models}

The 2-D models are meshed using the plane-stress option for the elements. The collar configuration is simulated with two layers of a $0.5-\mathrm{mm}$ thick mesh. For the coils, iron yoke, cylinder, insert and locking rods a 1-mm thick layer is meshed.

The prestress of the coils is obtained with given interference at the interfaces between the collars and the coil.

The external cylinder prestress is also simulated with an interference between the iron yoke and cylinder.

Magnet operation is simulated by loading the coils with the electro-magnetic forces computed with the same code. Iron saturation is taken into account.
No friction at all was considered between the different components in case of relative displacements. The mesh considers a one-quarter structure (with appropriate boundary conditions for the simulation of two layers of collars). We consider two possibilities for the plastic collars: low modulus of elasticity (7 GPa at room temperature, $8 \mathrm{GPa}$ at $1.9 \mathrm{~K}$ ), high modulus ( $20 \mathrm{GPa}$ at room temperature, $22 \mathrm{GPa}$ at $1.9 \mathrm{~K}$ ). We think these are the two limits of the possible range for plastic materials.

\section{B. Obtained Results}

The results of the computations are shown in Tables I-III.

The modulus of elasticity of the collars influences the rigidity of the collared coils. We can define a vertical rigidity as the ratio between a vertical force (i.e., the resulting reaction force developed by the compressed coils) and the corresponding vertical deformation of the collared coils. As explained in the introduction, all the vertical reaction forces are transmitted by the floating collars to the fixed ones via the packing rods. Therefore a change of the floating collar stiffness does not affect the vertical rigidity of the collared coils.

We can also define a horizontal rigidity as the ratio between a horizontal force applied to the collar shoulder and the corresponding horizontal deformation of the collared coils. The floating collars contribute to the definition of this rigidity. Therefore a change of the floating collar material generate a change of the horizontal rigidity.

The horizontal and vertical rigidity of the collared coils influences the global behavior of the assembled dipole because of the contacts between collars and iron yoke.

The horizontal stiffness of collared coils assembled using steel collars is $18000 \mathrm{~N} / \mathrm{mm}$ per mm length. That is to say we need two inward horizontal forces of $18000 \mathrm{~N}$ applied at each collar shoulder (right and left side) to decrease by one millimeter the horizontal overall dimension of a one millimeter thick slice of collared coils. The horizontal stiffness of mixed steel-plastic collared coils is $11500 \mathrm{~N} / \mathrm{mm}$ per mm length. This difference in stiffness of the collared coils explains the different behavior of the two structures. The effect is larger for the inner part of the structure (coil prestress, collar shoulder forces), is reduced for the outer part of the structure (iron yoke mating forces, shrinking cylinder tension). No significant differences are present in case of low or high modulus of elasticity of the plastic floating collar material.

1) At room temperature once the dipole is assembled the tension of the shrinking cylinder loads the inner part of the structure. The reaction to the shrinking cylinder force is only in part exerted by the iron yoke mating surfaces (the gap is closed at room temperature). The larger amount of the reaction is exerted by the collared coils that are compressed along their horizontal axis. Therefore the different rigidity of the collared coils results in different force distribution for the two structures.

2) At cold before the energization, the iron yoke gap is closed and the collared coils are just in contact with the iron yoke. This is due to the fact that the collars shrink more than the iron during the cool-down. Since the horizontal resulting forces exchanged by the collared 
coils and the iron yoke are very small, the effect of the different horizontal stiffness is reduced.

3) Finally once the dipole is powered to the nominal field, the collared coils expand horizontally resting against the iron yoke structure The iron yoke configuration is the same for both MBP1T_I and MBP1T_MSP; therefore structural behavior of the two is practically the same. To summarize the difference due to the collared coil stiffness is relatively small at room temperature and tends to reduce once the magnet is cold and during the powering.

\section{Possible Materials}

The features of a thermoplastic suitable for moulded floating collars are the following:

- good mechanical properties at cryogenic temperatures. The plastic collar is just a spacer filling the volume between two consecutive fixed ones. It is in contact neither with the coils nor with the iron yoke. Although such a floating collar does not see any force (or stress), we prefer, for safety reason, to use high strength plastics;

- conservation of the mechanical properties after irradiation;

- $\quad$ low affinity to moisture before injection;

- $\quad$ good fluidity to fill easily all the injecting mould cavity;

- $\quad$ sufficient flatness once extracted from the mould;

- mould temperature as low as possible and injection cycle as short as possible;

- $\quad$ low price of the raw material.

\section{A. Material Properties}

The tests are generally performed on samples given by the producers. The samples can have different shapes and dimensions. The injection point as well can be different in shape and position. As a consequence the cutting direction of the sample respect to the main injection stream can be different. All these factors can affect the reproducibility of the measured values. For this reason, when possible, we measured samples cut from injected test collars. The tested materials belong to different chemical families. For analogy, materials with different commercial names, but with similar chemical composition should present the same characteristics. To test the radiation resistance we assume the following beam conditions:

- Proton beam energy $2^{*} 7 \mathrm{TeV}$

- Beam intensity $2^{*} 540 \mathrm{~mA}$

- Annual proton loss $1.65^{*} 10^{11}$ protons per meter.

This means that the most exposed dipoles will receive a dose of 1.75 MGy in 25 years.

We tested or checked the available data [2]-[4] for ten possible thermoplastic materials. After the radiation resistance tests we concentrated our attention on three candidates. Tables IV-VI give the commercial name of the thermoplastic, the producer the
TABLE IV

COMmercial Name of Materials and Producers

\begin{tabular}{lll}
\hline Material & Type & \multicolumn{1}{c}{ Producer } \\
\hline Ixef & 1022 & Solvay \& Cie \\
\hline Ryton $^{\text {TM }}$ & R10-110BL & Phillips 66 \\
& R-4XT & Phillips 66 \\
\hline Ultradur $^{\text {TH }}$ & B 4300 G6 & BASF \\
\hline & B 4300 G10 & BASF \\
\hline
\end{tabular}

TABLE V

Mechanical Properties Before and AFter IRRAdiation. Being the RESIN THE CRITICAL FACTOR FOR THIS TEST THE IXEFTM AND THE RYTONTM USED WeRE NOT THE SAME GRADE OF TABLE IV. FOR THIS REASON AND FOR A CORRECT COMPARISON THE VALUE ON THE SPECIMEN BEFORE IRRADIATION HAS BEEN REPORTED. THE DATA OF RYTON ${ }^{\mathrm{TM}}$ IS NOT AT 3 MGy, BUT AT 5 MGy

\begin{tabular}{lcc}
\hline Material & $\begin{array}{c}\text { Modulus at } \\
\text { 0 Mgy Dose } \\
{[\mathrm{MPa}]}\end{array}$ & $\begin{array}{c}\text { Modulus at } \\
\text { 3 Mgy Dose } \\
{[\mathrm{MPa}]}\end{array}$ \\
\hline Ixef $^{\mathrm{TM}}$ & 11800 & 11400 \\
\hline Ryton $^{\mathrm{TM}}$ & 12100 & 12300 \\
\hline Ultradur $^{\mathrm{TM}} \mathrm{B} 4300 \mathrm{G} 10$ & 14470 & 9130 \\
\hline Ultradur $^{\mathrm{TM}} \mathrm{B} 4300 \mathrm{G} 6$ & 5330 & 5800 \\
\hline
\end{tabular}

TABLE VI

MATERIal Properties at RoOM TEMPERATURe (RT) AND 77 K

\begin{tabular}{lcc}
\hline Material & $\begin{array}{c}\text { Tensile modulus RT } \\
{[\mathrm{MPa}]}\end{array}$ & $\begin{array}{c}\text { Tensile modulus } 77 \mathrm{~K} \\
{[\mathrm{MPa}]}\end{array}$ \\
\hline 1022 & 20000 & - \\
\hline $\mathrm{R} 10-110 \mathrm{BL}$ & - & 20900 \\
\hline $\mathrm{R}-4 \mathrm{XT}$ & - & - \\
\hline $\mathrm{B} 4300 \mathrm{G} 6$ & 10000 & 8000 \\
\hline $\mathrm{B} 4300 \mathrm{G} 10$ & 16000 & 14000 \\
\hline
\end{tabular}

radiation resistance and some properties both at room temperature and at $77 \mathrm{~K}$.

\section{B. Technological Considerations}

Several requirements have to be fulfilled to have a successful injection. First of all the material has to be pre-dried to avoid the presence of moisture at the moment of the injection. Materials like Ultradur ${ }^{\mathrm{TM}}{ }^{1}$ with a higher degree of hygroscopy, require a longer preparation before using them respect to Ryton ${ }^{\mathrm{TM}}$ and Ixef $^{\mathrm{TM}}$. On the other hand Ryton ${ }^{\mathrm{TM}}$ and Ixef ${ }^{\mathrm{TM}}$ need a mould temperature above $120^{\circ} \mathrm{C}$ to crystallize instead of $60^{\circ} \mathrm{C}$ as Ultradur $^{\mathrm{TM}}$. Therefore an oil heating circuit is necessary and the temperature has to be continually monitored. This kind of equipment makes the mould more expensive.

All the three polymers show excellent performance for what concerns the planarity of the collars after moulding.

Ixef ${ }^{\mathrm{TM}}$ and Ryton ${ }^{\mathrm{TM}}$ present very small shrinkage during crystallization $(\sim 0.2 \%)$, thus guarantee a good dimensional performance and an easy design of the mould while for the other material the over-sizing necessary to compensate the dimensional reduction is more important $(\sim 1 \%)$.

\footnotetext{
${ }^{1}$ The name Ixef, Ryton, Ultradur are trademarks of Solvay, Phillips 66 and BASF respectively.
} 


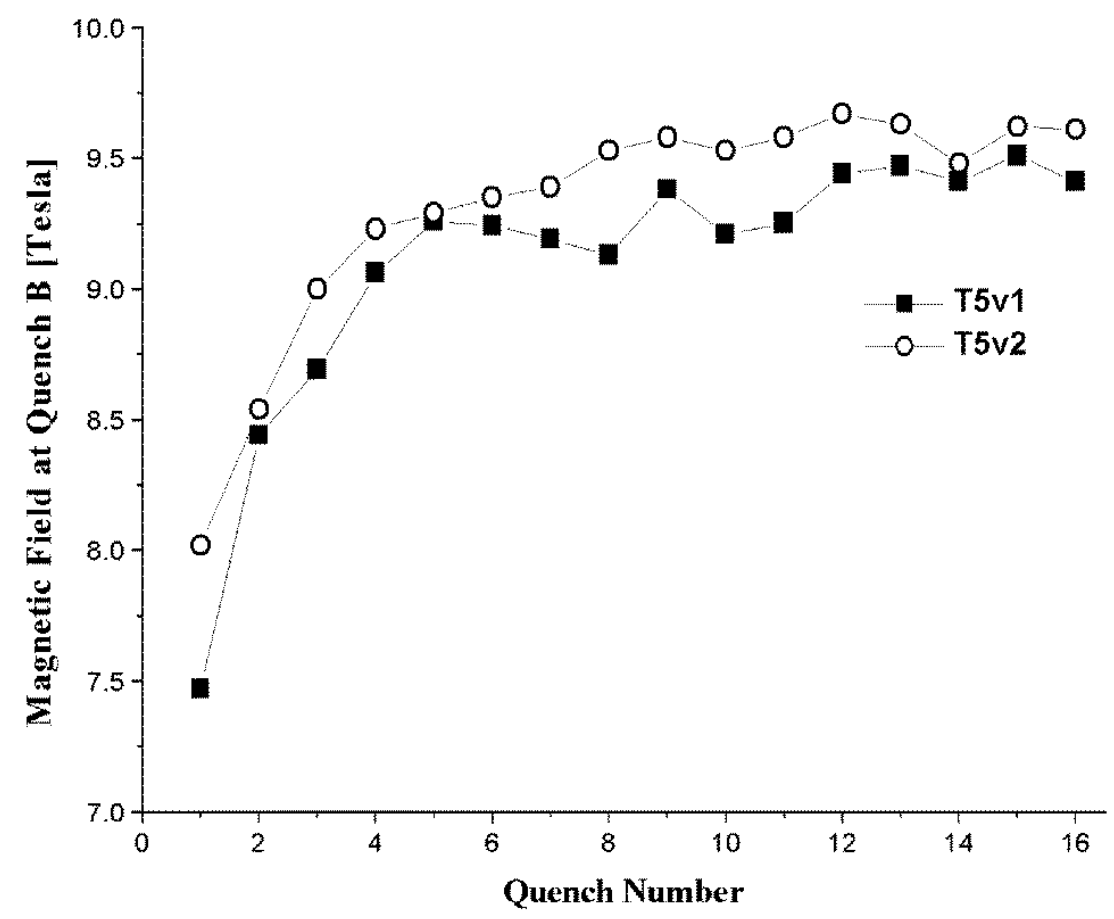

Fig. 2. Training quenches at $1.9 \mathrm{~K}$ for the two versions of MBSMT5 (16 Quenches). T5 v.1 with standard austenitic steel floating collar. T5 v.2 with plastic floating collars.

TABLE VII

INDICATIVE PRICE PER LITER OF THE SElECTED MATERIALS

\begin{tabular}{lc}
\hline Material & Indicative price per litre [CHF] \\
\hline xef $^{\mathrm{TM}} 1022$ & 16.4 \\
\hline Ryton $^{\mathrm{TM}} \mathrm{R} 10-110 \mathrm{BL}$ & 15.2 \\
\hline Ultradur $^{\mathrm{TM}} \mathrm{B} 4300 \mathrm{G} 10$ & 10.9 \\
\hline Ultradur $^{\mathrm{TM}} \mathrm{B} 4300 \mathrm{G} 6$ & 9.6 \\
\hline
\end{tabular}

\section{Cost of the Raw Material}

The following table gives the indicative cost per liter ${ }^{2}$ of the three polymers retained. The cost given here is the one for the purchase of quantities of about 10 tons. The purchase of larger quantities should imply some price reductions different from supplier to supplier.

The needed amount of polymer for the assembly of 1 meter of magnet is about 30-38 kg depending on the density (equivalent to a volume of about 201 ).

\section{Costs}

At this point we can estimate the price of the steel and plastic collars again using a LHC dipole as reference design.

We assume cost of $5 \mathrm{CHF} / \mathrm{kg}$ for the austenitic steel and the costs reported in Section IV for the plastic materials. It is also

${ }^{2}$ The price comparison is given here per volume unit since the density of the materials is different.

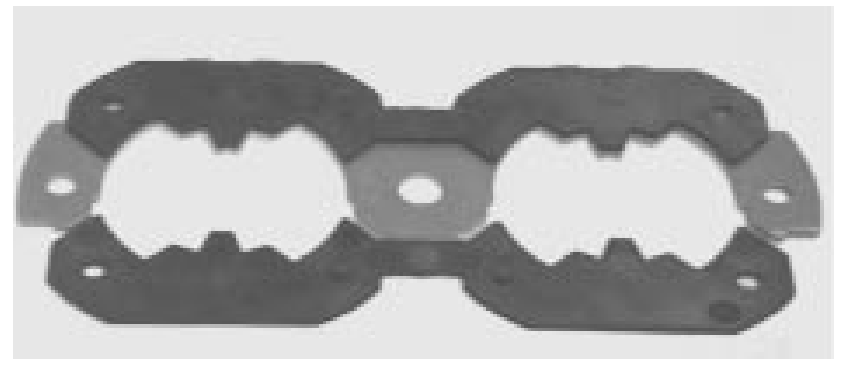

Fig. 3. The austenitic collar plus plastic collars made of Ryton ${ }^{\mathrm{TM}}$.

assumed that the price of one fine-blanking stroke is $1 \mathrm{CHF}$ while the cost of one injection is $0.8 \mathrm{CHF}$.

For the tooling we have a cost of about $150000 \mathrm{CHF}$ for a fine-blanking mould and about $35000 \mathrm{CHF}$ for an injection mould. For both the possibilities the cost of the tooling is therefore negligible considering the large amount of pieces to be produced. Considering the costs for the raw material and the costs of the manufacturing process we have:

- one fixed austenitic steel collar costs 6.34 CHF, - one floating austenitic steel collar costs 4.98 CHF,

- one floating plastic collar costs between 1.3 and 1.6 CHF depending on the cost of the polymer.

There are other possible savings more difficult to quantify:

- Dimensional inspections.

- Collar pack preparation. 
Since the floating collar becomes a simple longitudinal spacer the only critical dimension is its thickness. Therefore all the dimensional checks during the mass production can be largely reduced. The bulges of the floating collars lock into the corresponding holes of the fixed collars.

This assembly could be directly mounted around the coils without preparing any collar pack (no packing rods are needed). Finally the fixed collars could be flat, without any emboss. The tolerance on their height is very difficult to keep (tol. $\pm 0.02 \mathrm{~mm}$ ) and consequently represents a not negligible cost for the fineblanking. The embosses can be placed on the two sides of the injected floating collar and produced with extremely high reproducibility $( \pm 0.01 \mathrm{~mm})$.

\section{EXPERIMENTAL TEST}

In the frame of the LHC R\&D a twin-aperture short dipole model was built using austenitic steel fixed and floating collars (MBSMT5.V1). After the training the magnet was disassembled and re-collared using austenitic steel fixed collars and plastic floating collars made of Ixef ${ }^{\mathrm{TM}}$ in the straight part (MBSMT5.V2). The dipole ends were covered by steel fixed and floating collars as in the V1. Fig. 2 shows the training curves. In both the versions all training quenches were in the ends. Clearly the plastic collars did not deteriorate or change the dipole quenching performance.

\section{CONCLUSIONS}

Finite element computations show that a configuration with mixed plastic-austenitic collars has a behavior, in the straight cross section, close to that with only austenitic collars.

The computations are confirmed by an experimental result on short model. At least three thermoplastic materials could be used for the floating collar production. Although more tests are needed the long term behavior in the actual operative conditions, the advantages of the lower weight of the dipole and especially of the large cost reductions are very attractive and maybe considered for projects beyond LHC.

\section{REFERENCES}

[1] P. Fessia, D. Perini, R. Vuillermet, and C. Wyss, "Comparative study of different designs of the mechanical structure for the LHC main dipoles,", LHC Report, to be published.

[2] H. Schonbacher, B. Szeless, M. Tavlet, K. Humer, and H. W. Weber, "Results of radiation tests at cryogenic temperature on some selected organic materials for the LHC," CERN 1211 Geneva 23, Switzerland and Atominstitut der Osterreichischen Universitaten, 1020 Vienna Austria, CERN 96-05, July 4, 1996.

[3] M. Tavlet, A. Fontaine, and H. Schonbacher, "Compilation of radiation damge test data,", CERN 98-01, May 1998.

[4] H. Schonbacher and A. Stolarz-lzy, "Compilation of radiation damge test data,”, CERN 79-08, Aug. 1979. 